\title{
APLIKASI MODIFIKASI VARIAN "BIOTIN" UNTUK PENGHIJAUAN DAN TANAMAN OBAT KELUARGA DI KELURAHAN BERKAS, KOTA BENGKULU
}

\section{APLICATION OF "BIOTIN" VARIANT MODIFICATION FOR REFORESTATION AND FAMILY MEDICAL PLANTS IN SUB DISTRICT BERKAS, BENGKULU CITY}

\author{
Oleh: \\ Eko Sumartono, Merlian Zikri, Basuki Sigit Priyono \\ Fakultas Pertanian, Universitas Bengkulu \\ Email:eko_sumartono@unib.ac.id
}

\begin{abstract}
Consequences that arise as population growth and negative paradigm about fecal waste become one of unhealthy residential factors. However, if managed properly and correctly it can improve the welfare of the community. The management of biotic waste (biotin) into biotic and biococopit variations can be used to optimize the utilization of waste management. The management of this activity aims to cultivate environmental awareness, self-sufficiency of food and medicine, and optimization of narrow land use. The results to be achieved in this activity is community empowerment urban village Berkas is to improve the ability and skills of housewives in managing biotin variation as an effort to green the yard, coastal and family medical plants. Socialization is the initial stage of community empowerment. Counseling and training are the methods applied to this activity through personal and group approaches. Socialization is done by introducing variation of planting medium, plant type, and crop management. Meanwhile, the training that was carried out was planting, care and crop management. Optimization of narrow space utilization by utilizing biotin variation is expected to create a society with self-sufficient conditions of food and medicine. In addition, biotin variations become a new resource in the utilization of waste in the environment around urban village Berkas.
\end{abstract}

Keywords: empowerment, biotin, self-sufficient food, medicine plant

\section{PENDAHULUAN}

Seiring bertambahnya jumlah penduduk setiap tahun menimbulkan berbagai permasalahan dalam dinamika kehidupan. Pertambahan penduduk yang tidak sebanding dengan area pemukiman melahirkan pemukiman yang tidak sehat. Salah satu masalah yang timbul yaitu sampah atau kotoran (limbah tinja), hal tersebut lahir dari sanitasi dan aerasi yang kurang baik. Dampak buruknya terjadi penumpukkan limbah tinja setiap hari dan persepsi masyarakat bahwa limbah tersebut tidak dapat diolah. Namun, dibalik paradigma negatif mengenai limbah tinja terdapat potensi besar yang perlu dikembangkan dan diolah dengan baik.

Penelitian pemanfaatan limbah cocopeat untuk media tanam yang dilakukan oleh Irawan dan Kafiar (2015), menemukan bahwa media cocopeat pada dasarnya memiliki kemampuan mengikat dan kapasitas menyimpan air yang sangat kuat. Istomo dan 
Valentino (2012) juga menemukan cocopeat memiliki pori mikro yang mampu menghambat gerakan air lebih besar sehingga menyebabkan ketersediaan air lebih tinggi.

Limbah tinja berdasarkan kajian Riski (2015), menerangkan dengan mengilustrasi kotoran dari 3,5 juta penduduk di Surabaya dikumpulkan menjadi bank pupuk organik dan biogas, dari hasil uji coba $10 \mathrm{~kg}$ kotoran yang terkumpul dalam kondisi relatif murni menghasil sekitar 4-6 kg pupuk atau 40\% dari volume awal. Limbah kotoran manusia yang dianggap sebagai kotoran yang tidak berguna, ternyata mengandung nutrien yang sangat banyak. Setiap hari, kotoran manusia yang dibuang mengandung $90 \mathrm{~g}$ bahan organik (berupa $30 \mathrm{~g}$ karbon), 10 -12 g nitrogen, $2 \mathrm{~g}$ phosphor, dan $3 \mathrm{~g}$ kalium (Strauss, 2000). Kotoran manusia terdiri dari zat-zat organik sekitar $20 \%$ yang terdiri dari nitrogen, asam fosfat, sulfur dan lain-lain.Limbah ini sangat bermanfaat untuk pertumbuhan tanaman, pemanfaatan lumpur tinja sebagai pupuk organik dikenal dengan istilah "Biotin".

Modifikasi biotin menghasilkan variasi biotin dengan memanfaatkan keragaman limbah dengan harapan akan meningkatkan kualitas tumbuh tanaman dan mengurangi keberadaan limbah itu sendiri. Biotikar dan biococopit merupakan varian yang tidak begitu popular atau dikenal oleh masyarakat. Biotikar merupakan aplikasi dari biotinja campur sekam, sedangkan biococopit yaitu biotinja campur sabut kelapa (limbah dari kelapa disekitar pantai). Varian biotin ini diadaptasi berdasarkan situasi dan kondisi tlokasi pembinaan sebagai upaya penghijauan pekarangan, pesisir pantai dan nutrisi untuk tanaman (TOGA).

Kelurahan Berkas termasuk dalam kelurahan tertua, terletak di tepi Pantai Panjang Kota Bengkulu dengan luas sebesar 41,5 $\mathrm{Km}^{2}$ (Teluk Segara, 2017). Kondisi daerah yang semakin berkembang dan padat penduduk memungkinkan sulit untuk ditemuinya ruang terbuka hijau (RTH). Masyarakat di Kelurahan Berkas bermata pencarian sebagai nelayan, pekerja serabutan, pedagang, pegawai swasta dan pegawai negeri. Lingkungan masyarakat bertempat tinggal umumnya memiliki ruang pekarangan yang kecil dan sempit karena itu diperlukannya optimalisasi pemanfaatan ruang pekarangan dengan variasi TOGA. Disamping itu, Sajogyo (1994) menerangkan tanaman perlu pengolahan yang baik supaya memberikan hasil yang baik pula untuk sendiri ataupun dibutuhkan oleh masyarakat untuk dijadikan sebagai obatan.

Pemanfaatan pekarangan rumah merupakan alternatif mewujudkan kemandirian pangan dan obat di Kelurahan Berkas yang berada di pesisir pantai. Menurut penelitian bahwa lahan pasir pesisir pantai memiliki berbagai faktor pembatas dari segi sifat fisik, kimia dan biologi. Faktor pembatas berupa sifat fisik antara lain : tekstur tanah yang buruk, daya memegang air tanah sangat rendah karena luas permukaan yang kecil dan pori yang besar, laju perkolasi infiltrasi dan evaporasi tinggi, serta kondisi iklirn mikro dalarn tanah yang ekstrirn (Rosenberg, 1974; Oke, 1978; Sitorus et al,., 2008; Sumardi, 2008; Shi et al, 2005).). Menanam tanaman pangan dan obat di pekarangan dimaksudkan untuk memenuhi kebutuhan gizi keluarga tersebut dengan memanfaatkan halaman ruang yang tersisa. Herlianti (2014) menjelaskan usaha di pekarangan jika dikelola dengan intensif sesuai dengan potensi pekarangan maka dapat memenuhi kebutuhan konsumsi rumah tangga dan memberikan sumbangan pendapatan bagi keluarga.

Sasaran pemberdayaan ini pada kelompok masyarakat kecil yang perduli akan lingkungan dan penghijauan pada RTH dan lahan tidur guna menciptakan lingkungan yang asri, sejuk dan sehat. Pemberdayaan ini diselaraskan dengan program pemerintah guna membangun masyarakat yang mandiri baik itu kesehatan dan perekonomiannya. Tujuan dari pengabdian kepada masyarakat ini yaitu: 
1. Menumbuhkan kepedulian masyarakat khususnya ibu rumah tangga (IRT) 02 dan 03 Kelurahan Berkas terhadap pemanfaatan media tanam variasi biotin berdaya guna dengan bercocok tanam hortikultura dengan menggunakan polybag,

2. Optimalisasi potensi masyarakat dalam mengelola limbah melalui bercocok tanam dan optimalisasi pekarangan, RTH, dan TOGA sehingga lebih bermanfaat.

Manfaat dari pembinaan pengabdian kepada masyarakat ini antara lain yaitu meningkatkan kepedulian masyarakat terhadap lingkungan, alternatif usaha dalam upaya mensejahterahkan keluarga, mengoptimalkan pemanfaatan pangan dan TOGA pada pekarangan sempit.

\section{METODE PENGABDIAN}

Kegiatan pengembangan pengabdian masyarakat dilaksanakan bulan AprilNovember di RT 02 dan 03 pada Kelurahan Berkas, Kota Bengkulu. Kelompok sasaran dalam pengabdian yaitu ibu rumah tangga melalui pemanfaatan biotikar dan biococopit sebagai upaya penghijauan pesisir pantai dan tanaman obat keluarga (TOGA). Bibit tanaman yaitu bawang dayak (Eleutherine bulbosa), sambang dara (Excoecaria cochinchinensis), temu putih (Curcuma zedoaria), puding hitam (Graptophillum pictum). Tahapan kegiatan dalam mendukung pengabdian ini yaitu

1. Persiapan

Kegiatan persiapan sebelum dilaksanakanya Pengabdian kepada Masyarakat (PPM) yaitu sosialisasi terhadap IRT tentang pemanfaatan biotikar dan biococopit. Namun, sebelum sosialisasi dilaksanakan perlu diketahui pengetahuan dasar masyarakat mengenai biotikar dan biococopit sebagai tolak ukur pemahaman tentang materi yang akan di sosialisikan kepada masyarakat. Selanjutnya, tim pengabdian akan memberikan materi kiat-kiat dalam mengoptimalisasi biotikar dan biococopit sebagai upaya penghijauan pada RTH pesisir pantai dan pekarangan serta TOGA di Kel. Berkas.

2. Metode pelaksanaan

Metode yang digunakan dalam kegiatan PPM ini adalah penyuluhan dan pelatihan. Penyuluhan merupakan penyampaian materi pertanian yang disampaikan secara langsung atau tidak langsung dengan tujuan memberitahu, mau dan mampu menggunakan inovasi (Kusnadi, 2011). Tim pembina menerapkan metode pendekatan personal dan kelompok kelompok (Purwoko, 2009) sebagai metode penyuluhan yang tepat digunakan pada Kelurahan Berkas. Pelatihan dilaksanakan dengan pembagian polybag dan tanaman, pengisian media tanam biotikar dan bicocopit, dan penanaman tanaman pada RTH dan pekarangan.

\section{HASIL DAN PEMBAHASAN}

\section{Proses pencapaian hasil}

Secara terperinci proses pencapaian hasil melalui koordinasi dan partispasi mitra penerima yaitu

a. Terjalinnya koordinasi antara tim pelaksana dengan mitra penerima dalam aplikasi boitikar dan biococopit sebagai upaya penghijauan di RTH dan pekarangan serta TOGA kelurahan Berkas.

b. Modifikasi biotin terlaksana atas kerjasama dengan Instalasi Pengelolaan Lumpur Tinja (IPLT) Sawah Lebar Baru. 
c. Diskusi interaktif dengan Lembaga Pemberdayaan Masyarakat (LPM) mengenai sasaran kegiatan yang dicapai yaitu pemberdayaan masyarakat khususnya IRT dan PKK RT 02 dan 03.

d. Membantu penyediaan konsumsi dan pemesanannya selama berlangsung kegiatannya.

e. Memperkenalkan tim pelaksana kepada anggota ibu PKK.

Kepuasan mitra penerima benih, bibit dan media (biotikar dan biococopit) secara umum tergambarkan sebagai berikut:

a. Peserta antusias berdiskusi dan bertanya. Selain itu, peserta menginginkan diskusi tambahan terkait dengan program pembinaan yang disampaiakan walaupun kegiatan penyuluhan telah terlaksana.

b. Peserta meminta segera merealisasikan pemberian benih, bibit, dan bahan media setelah penyuluhan awal dilaksanakan.

c. Permintaan peserta untuk menjadwalkan penyuluhan pukul $15.30 \mathrm{WIB}$ di hari minggu dengan harapan semua IRT dan PKK 02 dan 03 menghadiri kegiatan yang dilangsungkan.

Penyuluhan dan pelatihan yang dilaksanakan meningkatkan pengelolaan manajemen pada IRT dan PKK Kelurahan Berkas. Secara umum terlihat pada:

a. Meningkatnya pengetahuan masyarakat penerima benih, bibit dan bahan media tanam. Terealisasi dengan transfer pengetahuan dalam memanfaatkan limbah kotoran manusia sebagai media tanaman.

b. Manajemen perawatan tanaman yang baik akan menghasilkan tanaman yang sehat apabila dilaksanakan dengan perawatan yang intensif.

Selanjutnya, tim telah berkoordinasi dengan LPM Kelurahan Berkas pada bulan April dan Mei 2017 bertujuan untuk memastikan secara spesifik target audien yang akan dilibatkan dan secara khusus menghasilkan:

a. Nama mitra penerima bibit dan bahan media tanam terlibat dalam PPM Pembinaan Universitas Bengkulu.

b. Jenis-jenis bibit TOGA yang dapat ditanam pada pekarangan rumah sehingga membantu kebutuhan kesehatan keluarga.

c. Permasalahan yang sering muncul dilapangan adalah rendahnya pengetahuan warga tentang manfaat menanam dipekarangan dan penggunaan media bahan tanam.

d. Penjadwalan acara penyuluhan tentang sosialisasi dan pelatihan mengenai pengenalan dan manfaat modifikasi biotin (lumpur tinja) menjadi berbagai varian untuk penghijauan dan TOGA di RT 02 dan 03 Kelurahan Berkas.

e. Kegiatan PPM Pembinaan pada IRT 02 dan 03 yang akan dilaksanakan menyebabkan anggota RT lainnya juga tertarik untuk daftar sebagai penerima bibit dan bahan media lumpur tinja. Namun karena program PPM Pembinaan ini terbatas, maka tim memberikan sebagian kecil ke ibu-ibu RT lainnya dalam jumlah yang terbatas dan akan memberikan kesempatan selanjutnya jika ada hal yang sama akan diajukan pada PPM Pembinaan 2018.

\section{Sosialisasi manfaat TOGA dan HORTIKULTURA dengan media biotin (biotikar dan biococopit)}

Pelaksanaan sosialisasi dilaksanakan pada Mei 2017. Secara generalisasi untuk materi sosialisasi disampaikan yaitu (1) manfaat menanam TOGA dan Hortikultura dengan media biotikar dan biococopit pada pekarangan dan RTH; (2) Kelebihan dan kekurangan pada bahan media tanam; (3) Menejemen perawatan dan vertikultur. Sosialisasi berjalan sesuai harapan dengan tingkat antusiasme peserta yang tinggi, terlihat dengan munculnya 
pertanyaan seputaran materi sosialisasi. Antara lain pertanyaan seperti tanaman apa yang akan di tanam dan di pekarangan, perlukah media lain untuk menanam, unsur hara pada biococopit dan biotikar, cara mencegah penyakit tanaman, dst.

Mitra penerima disarankan untuk mencoba beberapa jenis racun tradisional dan pengelolaan tanaman inang disekitar rumah. Alternatif yang ditawarkan adalah penyemprotan air seni sapi yang didiamkan selama 2 minggu denga perbandingan 1:6 dengan campuran daun tembakau, kunyit, atau daun nimba. Sementara, percepatan pertumbuhan tunas dan akar menggunakan rendaman air dicampur bawang merah dan sedikit bawang putih dan cucian beras. Setelah berlangsungnya sosialisasi, maka tim Pembina segera menganalisa kebutuhan pembelian benih, bibit dan media tanam yang akan diserahkan kepada mitra penerima yaitu IRT RT 02 dan 03 Kel. Berkas. Adapun rincian yang dibutuhkan yaitu:

a. Pembelian Polybag untuk 25 orang penerima benih, bibit dan bahan media lumpur tinja pada tanggal 25 Mei 2017.

b. Pemesanan bibit Bawang dayak, Sambang dara, Sirsak, Kunyit putih, Jahe, Temu Putih dan Tanaman kayu-kayuan pada awal bulan juni 2017 dan diambil pada tanggal 19 Juni 2017.

c. Pembelian benih, dilakukan pada tanggal 17 juni 2017 untuk benih dan bibit bawang dayak saja dikarenakan stok benih lain untuk sambang dara, sirsak, tanaman kayu, kunyit putih, jahe, temu putih dan tanaman kayu-kayuan belum memenuhi kualitas tanaman yang dikehendaki. Pembelian benih selanjutnya dilaksanakan pada tanggal 19 Juni 2017. Beberapa jenis tanaman yang akan dibagikan kepada mitra penerima ditunjukkan pada Gambar 1.

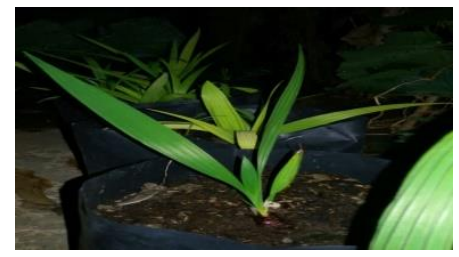

a. Bawang Dayak

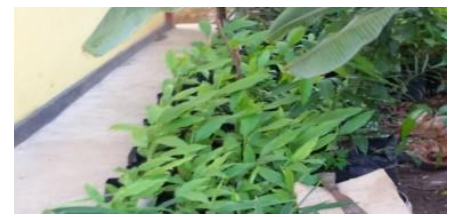

d. Temu Putih

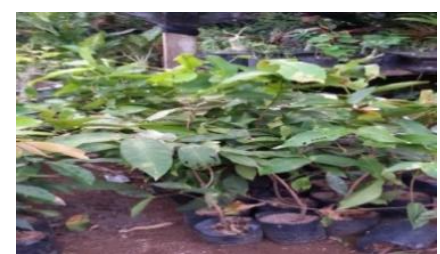

b. Tanaman kayu-kayuan

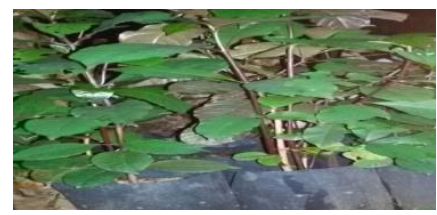

e. Puding Hitam

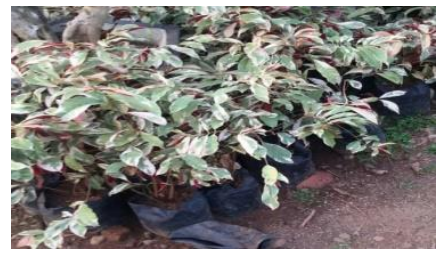

c. Sambang Dara

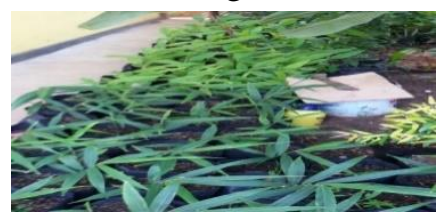

f. Tanaman siap diberikan ke mitra

Gambar 1. Beberapa bibit tanaman yang akan dibagikan kepada mitra penerima

\section{Pengangkutan biotin (biotikar dan biococopit)}

Koordinasi dengan Instalasi Pengelolaan Lumpur Tinja (IPLT) Kelurahan Berkas dan tim Pembina pada tanggal 20 Juni 2017 sehingga terkumpulnya 70 karung media tanam biotin yang akan diolah menjadi biotikar dan biococopit. Proses pengangkatan memerlukan dua kali pengangkutan ke lokasi mitra penerima. Pada tanggal 29 Juni 2016 biaya pelunasan transport angkut, tenaga kerja dan pembagian pupuk lumpur tinja. Proses pengangkatan dan pengangkutan pada Gambar 2. 


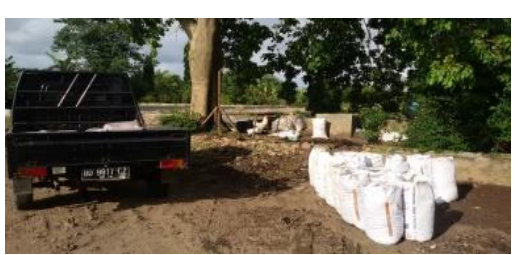

a. Pengangkutan media tanam

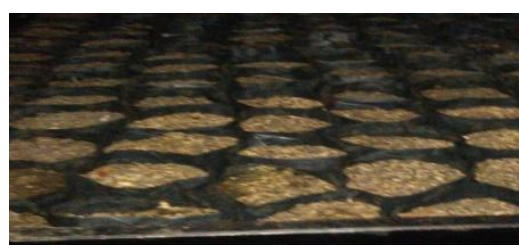

c. Gambar Biotikar dan Biococopeat Campur (dalam Polibag)

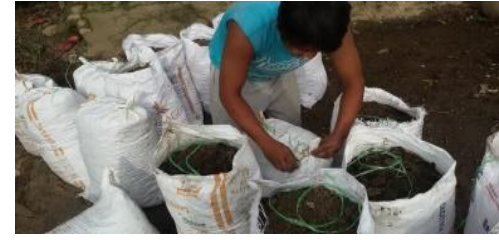

b. Packing media biotin kedalam karung
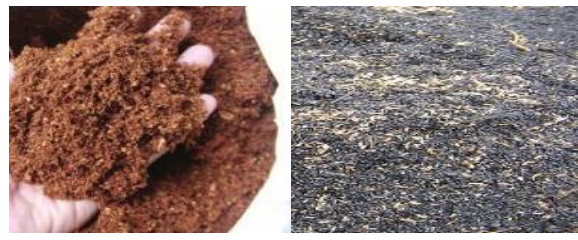

d. Cocopeat dan Sekam Bakar

Gambar 2. Proses pengangkatan dan pengangkutan biotin dan biotikar serta biococopeat

\section{Pembagian bibit tanaman}

Tim pembina dan LPM Kelurahan Berkas membagikan bibit tanaman kepada IRT RT 02 dan 03 dengan tujuan memberikan kesejukan dan keasrian rumah pada mitra penerima. Pelaksanaan pemberian bibit dikerjakan selama bulan Juni-Juli 2017. Selain bekerjasama dengan LPM, tim pembina juga bekerjasama dengan mahasiswa KKN yang berkediaman di lokasi pelaksanaan pembinaan. Gambar 3 menunjukkan pembagian bibit kepada mitra penerima.

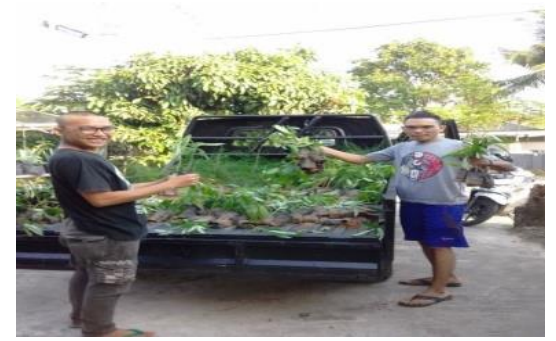

a. Pengangkutan bibit kepada mitra

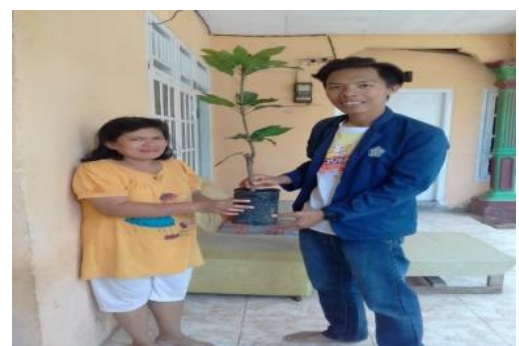

b. Pembagian bibit kepada Ibu RT

Gambar 3. Pembagian bibit kepada IRT kel. Berkas

\section{Pelatihan penanaman dan praktik lapangan dalam manajemen perawatan}

Pelatihan penanaman dan manajemen perawatan dilaksanakan pada awal bulan Oktober. Kegiatan pelatihan ini berjalan dengan baik dan lancar, namun proses berlangsungnya kegiatan terdapat beberapa permasalahan yaitu:

a. Pelaksanaan pelatihan penanaman dan praktek lapangan manajemen perawatan yang dilaksanakan pada halaman depan rumah RT 02 dan 03 Kelurahan Berkas Kota Bengkulu relatif sempit sehingga beberapa ibu-ibu yang dibantu oleh bapak-bapak melakukannya di pinggir jalan. 
b. Sebagian IRT telah mengisi polibag dengan tanah sehingga proses dan tata cara pelatihan diikuti oleh IRT yang belum melakukan pengisian tanah ke dalam polibag.

c. Minimnya pengetahuan dalam merawat tanaman pada IRT.

d. Pelaksanaan praktek relatif singkat karena terkendala hujan saat praktek manajemen perawatan.

Praktik manajemen perawatan di fokuskan pada proses perawatan yang dimulai dari proses perkecambahan menjadi bibit, pemeliharaan dan panen. Perawatan saat proses perkecambahan harus memperhatikan kelembaban dan sinar matahari yang cukup. Aturan ini agar proses perkecambahan berjalan baik. Pada beberapa jenis tanaman perlu dilakukannya skarifikasi benih. Skarifikasi benih merupakan salah satu upaya pretreatment atau perlakuan awal pada benih yang ditujukan untuk mematahkan dormansi dan mempercepat terjadinya perkecambahan benih yang seragam (Schmidt, 2000). Pada pagisiang hingga sore hari dilaksanakan penyiraman selama 10 hari hingga benih berkecambah dengan baik. Setelah benih berkecambah maka kegiatan penyiraman dikurangi pagi dan sore. Selanjutnya pada hari ke 21 penyiraman dilakukan sore hari saja sampai siap pindah setelah bibit berumur lebih dari 30 hari.

Kegiatan selanjutnya, perawatan dilaksanakan setelah bibit disapih kedalam polibag yaitu satu bibit tanaman yang telah di seleksi dan siap ditanam. Pemeliharaan dilakukan setiap dua hari sekali yakni penyiraman dan di letakkan dibawah sinar matahari yang cukup selama tanaman mulai berbunga dan berbuah. Sebaiknya di setiap penyiraman menggunakan air bilasan beras dan seminggu sekali dicampur dari gilingan bawang merah agar perakaran dan perkembangan tanaman semakin cepat besar. Penyemprotan dilakukan seminggu sekali dengan menggunakan larutan bawang merah dicampur daun nimba atau pestisida nabati lainnya.

Selama pemeliharaan oleh ibu-ibu sebaiknya tidak mecampur pupuk dengan bahan kimia lainnya sehingga diharapkan dapat menghasilkan tanaman organik yang sehat. Menjelang panen sebaiknya rutin diberikan tambahan pupuk lumpur tinja organik yang baru sehingga nutrisi tidak berkurang dan penambahan penyiraman dengan menggunakan siraman air perasan beras dan larutan bawang merah. Agar hasil panenan maksimal sebaiknya dilakukan penyiraman 2 kali sehari selama pembuahan. Lakukan penyemprotan dengan mengguanakan pestisida nabati agar tanaman lebih baik dan hindari menggunakan pestisida berbahan kimiawi untuk memperoleh tanaman organik yang sehat.

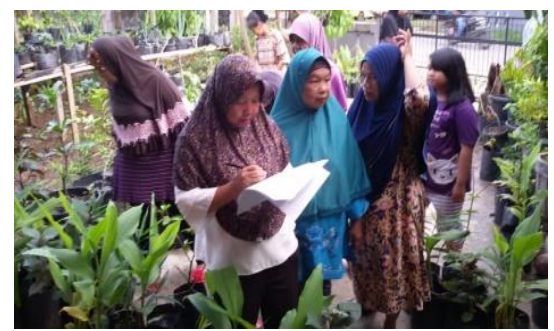

Gambar 4. IRT melaksanakan pemeriksaan dan perawatan tanaman

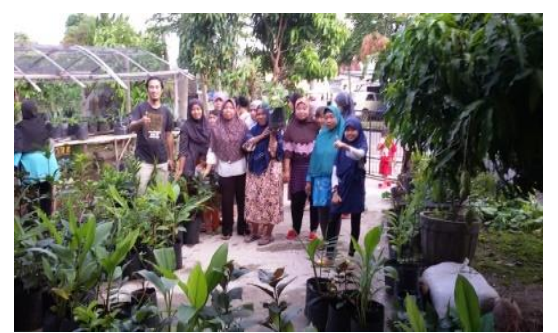

Gambar 5. IRT yang menerima bibit dengan media tanam biotikar dan biococopit 



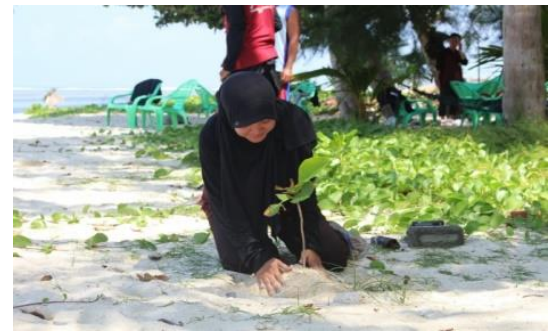

Gambar 6. Penanaman pada kawasan pantai di Kelurahan Berkas

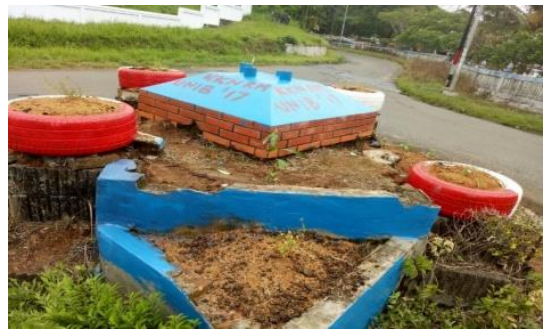

Gambar 7. Hasil penanaman pada kawasan RT H di RT 02 dan 03 Kelurahan Berkas

\section{KESIMPULAN DAN SARAN}

\section{Kesimpulan}

Secara keseluruhan kesimpulan dan saran dalam kegiatan PPM Pembinaan antara lain:

a. Menambah pengetahuan masyarakat terhadap pemanfaatan biotin dengan memodifikasi menjadi biotikar dan biococopit sebagai media tanaman hortikultura yang ditanam pada pekarangan rumah dan RTH Kelurahan Berkas serta manajemen perawatannya.

b. Menumbuhkan kepedulian masyarakat pada kelompok IRT dan PKK dilingkungan RT 02 dan 03 Kelurahan Berkas Kota Bengkulu terhadap pemanfaatan lumpur tinja (biotin) menjadi sumberdaya guna baru untuk bercocok tanam menggunakan polybag.

c. Mitra penerima yaitu IRT dan PKK senang dalam mengaplikasikan serta mengimplementasi pengetahuan yang diperoleh dari kegiatan membuat biococopeat dan biotikar yang telah dilakukan.

d. IRT dan PKK sangat antusias dan menyambut baik adanya PPM Pembinaan.

\section{Saran}

IRT dan PKK terus memanfaatkan pekarangan rumah dengan menanam tanaman hortikultura dan TOGA serta perlu ditingkatkan lagi secara terus menerus menanam tanaman dengan tujuan meringankan beban ekonomi keluarga. Disamping itu memberikan pemahaman baru tentang pemanfaatan media disekitar lingkungan sebagai media alternatif yang cocok untuk dikembangkan tanpa harus tergantung pada pupuk kandang (kotoran ternak) dan pupuk anorganik lainnya.

\section{DAFTAR PUSTAKA}

Herlianti, R, 2014, Dampak pemanfaatan pekarangan dengan tanaman sayuran terhadap pengeluaran pangan rumah tangga (studi kasus di Desa Bukit Peninjauan 1 Kecamatan Sukaraja Kabupaten Seluma, [Skripsi], Bengkulu (ID): Pertanian, Universitas Bengkulu (tidak dipublikasikan).

Irawan, A, dan Yeremias, K, 2015, Pemanfaatan Cocopeat dan Arang Sekam Padi sebagai Media Tanam Bibit Cempaka Wasian (Elmerrilia ovalis), Prosiding Seminar Nasional Masyarakat Biodiversitas Indonesia, Vol. 1(4): 805-808.

Istomo, Valentino N, 2012, Pengaruh perlakuan kombinasi media terhadap pertumbuhan anakan tumih (Combretocarpus rotundatus (Miq.) Danser), Jurnal Silvikultur Tropika, Vol. 3(2): 81-84. 
Kusnadi, D, 2011, Dasar-dasar penyuluhan pertanian [Internet], [diacu 2017 Oktober 28], Tersedia dari: Http://STPP-Bogor.ac.id/Userfiles/file/modul\%20dasar\%20penyu luhan\%20(dk), pdf.

Teluk Segara, 2017, Monografi Kecamatan Teluk Segara, Bengkulu (ID): Bengkulu.

Purwoko, A, 2009, Dasar-dasar penyuluhan pertanian, Badan Penerbit Fakultas Pertanian (ID): Universitas Bengkulu.

Riski, P, 2015, Kotoran manusia diubah jadi pupuk dan energi di tempat ini (Surabaya), Mongabay Indonesia, [diacu 2017 Oktober 28], Tersedia dari http://www.mongabay.co.id/2015/04/20/kotoran-manusia-diubah-jadi-pupuk-danenergi-di-tempat-ini/.

Sajogyo, 1994, Menuju gizi baik yang merata di pedesaan dan di kota, Gadjah Mada Press, Yogyakarta.

Rosenberg, N.J, 1974, Microclimate the Biological Enviroment, London: Longman.

Shi Z, Li Y, Wang RC, Makeschine F. 2005. Assessment of Temporal and Spatial Variability of Soil Salinity in a Coastal Saline Field. Environmental Geology. vol 48(2): 171-178.

Sumardi, 2008, Prinsip Silvikultur Reforestasi dalam Rehabilitasi Formasi Gumuk Pasir di Kawasan Pantai Kebumen, Prosiding Seminar Nasional Silvikultur Rehabilitasi Lahan: Pengembangan Strategi untuk Mengendalikan Tingginya Laju Degradasi Hutan, 24-25 November 2008, Yogyakarta: Fakultas Kehutanan, Universitas Gadjah Mada, hal. 58-65.

Schmidt, L, 2000, Pedoman penangan benih tanaman hutan tropis dan subtropic, Diterjemahkan oleh Dikrektorat Jendral Rehabilitasi Lahan dan Perhutanan Sosial Departemen Kehutanan. PT Gramedia (ID), Jakarta.

Strauss, M, 2000, Human Waste (Excreta and Wastewater) Reuse, EAWAG/SANDEC, Duebendorf, Switzerland. 